\title{
Transcatheter valve-in-valve tricuspid valve replacement via internal jugular and femoral approaches
}

\author{
Stephanie L. Mick, MD, ${ }^{a}$ Samir Kapadia, MD, ${ }^{\mathrm{b}}$ Murat Tuzcu, MD, ${ }^{\mathrm{b}}$ and Lars G. Svensson, MD, PhD, ${ }^{\mathrm{a}}$ \\ Cleveland, Ohio
}

Reoperation purely for right-sided heart failure with tricuspid valve disease carries an increased risk of death. We describe a patient who underwent percutaneous tricuspid valve-in-valve insertion via transfemoral and transjugular approaches.

\section{CASE DESCRIPTION}

The patient is an 80-year-old woman with a history of rheumatic heart disease requiring mitral valve replacement 34 years before presentation with a Bjork-Shiley valve. Seven years before presentation, she underwent tricuspid valve replacement with a no. 27 Medtronic Mosaic valve along with a maze procedure and permanent pacemaker implantation. Three years later, she underwent lumpectomy and radiation for breast cancer.

Other history included multiple pulmonary emboli, thoracic outlet syndrome, and neuropathic lower extremity pain with right foot drop. The year before presentation, she began to experience lower extremity edema, ascites, and lack of appetite, and was found to have prosthetic tricuspid valve stenosis and insufficiency. On presentation, she exhibited New York Heart Association functional class IV symptoms, was wheelchair-bound, and unable to undergo exercise testing.

Her echocardiogram showed an ejection fraction of $55 \%$, $2+$ tricuspid regurgitation, and severe stenosis with peak and mean gradients of $20 \mathrm{~mm} \mathrm{Hg}$ and $16 \mathrm{~mm} \mathrm{Hg}$ with reversal of hepatic systolic flow. Coronary angiography revealed no significant coronary artery disease. Pulmonary function testing demonstrated restrictive dysfunction (forced expiratory volume after 1 second of expiration $\left[\mathrm{FEV}_{1}\right] 0.88 \mathrm{~L}, 39 \%$ of predicted) and severely reduced diffusing capacity of lung for carbon monoxide (DLCO $5.24 \mathrm{~mL} / \mathrm{min} / \mathrm{mm} \mathrm{Hg}, 25 \%$ of predicted). Given her advanced age and comorbidities, she was judged to be at excessively high risk to undergo cardiac surgery at multiple

From the Departments of Thoracic and Cardiovascular Surgery ${ }^{\mathrm{a}}$ and Cardiovascular Medicine, ${ }^{\mathrm{b}}$ Heart and Vascular Institute, Cleveland Clinic, Cleveland, Ohio.

Disclosures: Authors have nothing to disclose with regard to commercial support.

Received for publication Oct 23, 2013; revisions received Dec 11, 2013; accepted for publication Dec 17, 2013; available ahead of print Feb 19, 2014.

Address for reprints: Stephanie L. Mick, MD, Department of Thoracic and Cardiovascular Surgery, Heart and Vascular Institute, Cleveland Clinic, 9500 Euclid Ave,

Desk J4-1, Cleveland, OH 44195 (E-mail: micks@ccf.org).

J Thorac Cardiovasc Surg 2014;147:e64-5

$0022-5223 / \$ 36.00$

Copyright (C) 2014 by The American Association for Thoracic Surgery

http://dx.doi.org/10.1016/j.jtcvs.2013.12.072

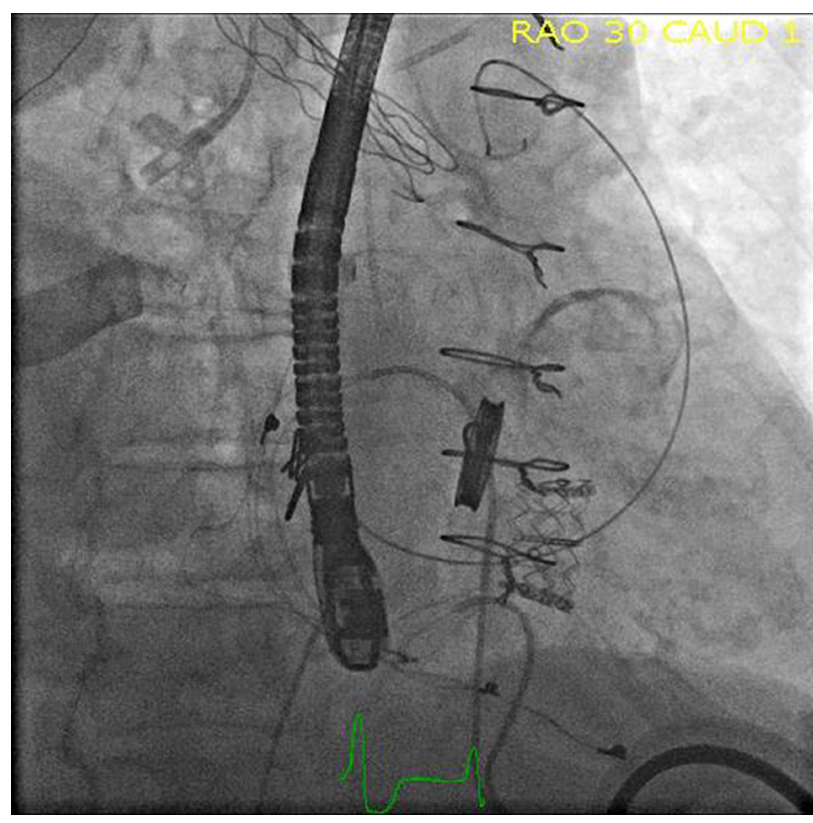

FIGURE 1. Sapien valve seated several millimeters within Mosaic valve after circular radiopaque markers.

institutions and she presented to us for transcatheter intervention.

The procedure was performed under general anesthesia. Our initial approach was via a 7-Fr sheath in the right internal jugular vein. We placed a Berman catheter into the right ventricle and measured a $15-\mathrm{mm} \mathrm{Hg}$ tricuspid valve gradient by simultaneous right ventricle-right atrial pressures. The Berman was advanced into the right pulmonary artery and we exchanged the sheath for a 24-Fr Edwards sheath over an Amplatz extra stiff wire. The Edwards Sapien delivery system with a mounted 26-mm valve (Edwards Lifesciences, Irvine, Calif) was delivered across the Mosaic valve. Using fluoroscopy and the post markers on the prosthetic valve as a reference point and transesophageal echocardiography guidance, the valve was deployed during rapid ventricular pacing. The Edwards Sapien valve was seated at the tips of the Mosaic valve posts (Figure 1). On observation over time, it appeared to migrate in the ventricular direction. We did not feel confident about its stability in this position and elected to place a second valve. We were concerned about the risk of dislodging the device on crossing the valve with a second device and took preventive measures by placing a 20/6 Z-med balloon into the RV via the internal jugular sheath to be used 


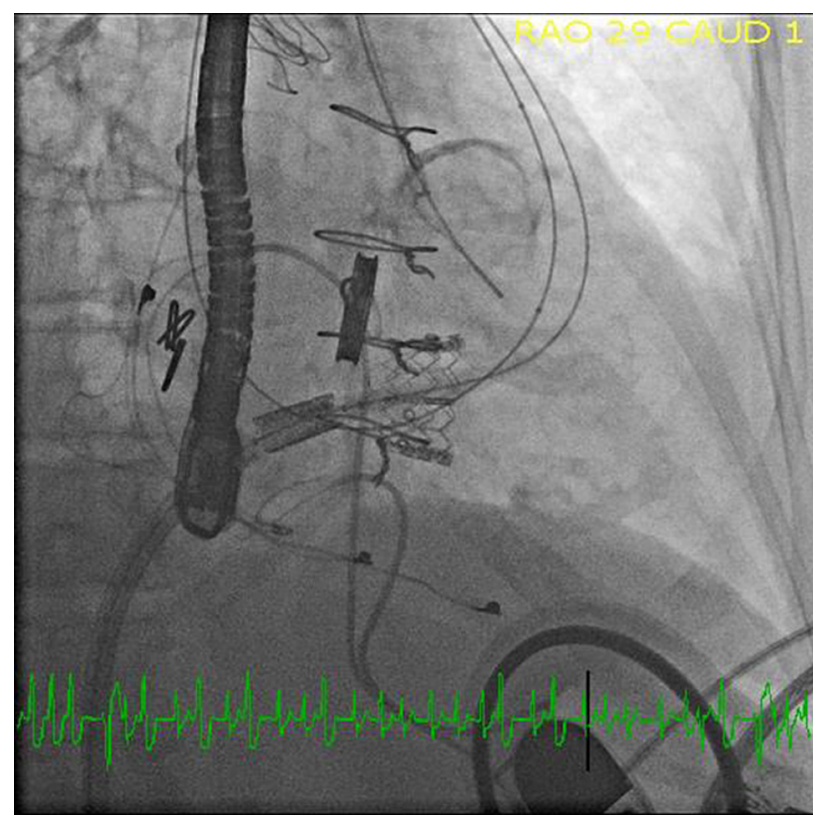

FIGURE 2. Advancing Sapien valve through Mosaic and Sapien valves via the femoral vein with Z-med balloon in position via the internal jugular vein.

emergently in the case of impending dislodgement of the first device. Then, via a 24-Fr Edwards sheath the right femoral vein, we placed a second Amplatz extra stiff wire into the right pulmonary artery. We inserted another no. 26 Sapien valve into the Mosaic and Sapien valves (Figure 2) without incident, removed the Z-med balloon, and deployed the valve. After deployment, transesophageal echocardiography confirmed a well-placed and seated valve with minimal tricuspid regurgitation. The tricuspid valve gradient decreased to $2 \mathrm{~mm} \mathrm{Hg}$ and the central venous pressure, which was $33 \mathrm{~mm} \mathrm{Hg}$ at the start of the procedure, decreased to $13 \mathrm{~mm} \mathrm{Hg}$.

After the procedure, the patient was discharged home with improved functional status, edema, and appetite.

\section{COMMENT}

The first human percutaneous transcatheter tricuspid valve-in-valve implantation was described by Van Garsse and colleagues ${ }^{1}$ using an Edwards Sapien valve and internal jugular access. Since then, transatrial and transfemoral methods have been described as well as the use of the Melody valve in this application. There are still less than 40 cases reported in the literature; tricuspid valve-in-valve implantation is still in its infancy. ${ }^{2}$ The femoral approach may be favored in cases of relatively vertically oriented tricuspid valves, ${ }^{2}$ however, in general, crossing the valve in this approach is believed to be more technically challenging because of the acute angle the catheter must take from the inferior vena cava through the valve to the right ventricle. ${ }^{3}$ We accepted this technical challenge as the risk of embolizing the first Sapien valve warranted prophylactic maneuvers via the internal jugular vein.

Troubleshooting maneuvers during transatrial deployment have been described, ${ }^{4}$ however, to our knowledge, this is the first description of valve-in-valve deployment both via the internal jugular and femoral veins, along with the prophylactic insertion of a right ventricular balloon. We believe that it is important to report potential challenges and their management as this technique continues to evolve so that all who perform these procedures can benefit from others' experience. Since this case we have performed 1 additional successful tricuspid valve-in-valve replacement through the femoral vein.

\section{References}

1. Van Garsse LA, Ter Bekke RM, van Ommen VG. Percutaneous transcatheter valve-in-valve implantation in stenosed tricuspid valve bioprosthesis. Circulation 2011;123:e219-21.

2. Hoendermis ES, Douglas YL, van den Heuvel AF. Percutaneous Edwards SAPIEN valve implantation in the tricuspid position: case report and review of literature. EuroIntervention. 2012;8:628-33.

3. Salizzoni S, La Torre M, Barbero C, Marra WG, Moretti C, D'Amico M, et al. Transjugular tricuspid valve-in-valve implantation. Heart Lung Circ. 2013;22:1036-9.

4. Cocchieri R, Wiegerinck EM, de Groot JR, Bouma BJ, Marsman M, de Mol BA et al. Troubleshooting in transatrial tricuspid valve-in-valve implantation. Ann Thorac Surg. 2012;94:1349-52. 